\title{
The YAP1 Homolog-Mediated Oxidative Stress Tolerance Is Crucial for Pathogenicity of the Necrotrophic Fungus Alternaria alternata in Citrus
}

\author{
Ching-Hsuan Lin, Siwy Ling Yang, and Kuang-Ren Chung \\ Citrus Research and Education Center, and Department of Plant Pathology, Institute of Food and Agricultural Sciences \\ (IFAS), University of Florida, 700 Experiment Station Rd., Lake Alfred 33850, U.S.A.
}

Submitted 26 January 2009. Accepted 23 April 2009.

\begin{abstract}
Citrus brown spot disease is caused by the necrotrophic fungus Alternaria alternata. Its pathogenic capability has been thought to depend exclusively on the production of host-selective ACT toxin. However, circumvention of plant defenses is also likely to be important for the disease process. To investigate the fungal response to host-generated reactive oxygen species (ROS), we cloned and characterized the $A a A P 1$ gene of $A$. alternata, which encodes a polypeptide resembling yeast YAP1-like transcriptional activators implicated in cellular responses to stress. Expression of the $A a A P 1$ gene in a wild-type strain was primarily induced by $\mathrm{H}_{2} \mathrm{O}_{2}$ or ROS-generating oxidants. Using a loss-of-function mutation in the $A a A P 1$ gene, we demonstrated an essential requirement for oxidative tolerance during the host invasion step. Mutants lacking $A a A P 1$ showed increased sensitivity to $\mathrm{H}_{2} \mathrm{O}_{2}$ and loss of fungal pathogenicity. The $\triangle A a A P 1$ null mutant did not cause any visible necrotic lesions on wounded or unwounded leaves of citrus cv. Minneola. Compared with the wild type, the null mutant displayed lower catalase, peroxidase, and superoxide dismutase activities. All mutant phenotypes were restored to the wild type in fungal strains expressing a functional copy of $A a A P 1$. Upon exposure to $\mathrm{H}_{2} \mathrm{O}_{2}$, the AaAP1::sGFP (synthetic green fluorescent protein) fusion protein became localized in the nucleus. Inoculation of the mutant with NADPH oxidase inhibitors partially restored fungal pathogenicity. Our results highlight the global regulatory role of a YAP1 homolog in response to oxidative stress in $A$. alternata and provide insights into the critical role of ROS detoxification in the pathogenicity of A. alternata.
\end{abstract}

All organisms with an aerobic lifestyle produce harmful reactive oxygen species (ROS), primarily superoxide $\left(\mathrm{O}_{2}^{-}\right)$and hydrogen peroxide $\left(\mathrm{H}_{2} \mathrm{O}_{2}\right)$, as an inevitable consequence of physiological metabolism (Apel and Hirt 2004). Thus, activation of detoxification systems that scavenge ROS, maintenance of reduced redox states within subcellular microenvironments, and repair of ROS-triggered damage are absolutely required to ensure survival of cells under aerobic conditions (Mittler 2002). Among ROS, $\mathrm{H}_{2} \mathrm{O}_{2}$ is less toxic but stable and able to pass freely through membranes (Branco et al. 2004). Hydro-

Corresponding author: K.-R. Chung; Telephone: +1.863 .956 .1151 ext. 1369; Fax: +1.863.956.4631; E-mail krchung@ufl.edu

* The $\boldsymbol{e}$-Xtra logo stands for "electronic extra" and indicates that three supplementary figures are published online. gen peroxide can further react with $\mathrm{O}_{2}^{-}$via the Haber-Weiss reaction or with metal ions via the Fenton pathway (Imlay 2003) to generate the extremely toxic hydroxyl radical, thus exacerbating the cellular toxicity of $\mathrm{H}_{2} \mathrm{O}_{2}$. During plant-microbe interactions, the production of $\mathrm{H}_{2} \mathrm{O}_{2}$ by a specific plasma membrane NADPH oxidase of plants is termed the hypersensitive reaction (HR), leading to programmed cell death and cellular defense against pathogen attack (Greenberg 1997). When produced in excess, ROS can also serve as secondary messengers in the pathogen-response signal transduction pathway (Neill et al. 2002; Veal et al. 2007). HR plays a critical role in plant defense against saprophytic microorganisms and biotrophic phytopathogens, yet it is less effective against necrotrophic phytopathogens (Glazebrook 2005). Most necrotrophic fungi produce toxins or cell-wall-degrading enzymes that kill host cells prior to invasion and obtain nutrients exclusively from dead tissues (Divon and Fluhr 2007). Indeed, ROS have been proposed to facilitate plant colonization by necrotrophic pathogens such as Botrytis cinerea and Sclerotinia sclerotiorum (Govrin and Levine 2000).

Alternaria alternata is a ubiquitous necrotroph comprising at least seven pathogenic variants, each producing unique hostselective toxins and causing disease on different host plants (Hatta et al. 2002; Ito et al. 2004; Kohmoto et al. 1991). On citrus, A. alternata has two distinct pathotypes. The rough lemon pathotype, producing the host-selective ACRL toxin, is pathogenic only to lemon (Citrus jambhiri Lush) and Rangpur lime (Citrus $\times$ limonia Osbeck). By contrast, the tangerine pathotype of $A$. alternata, which produces the host-selective ACT toxin with a core 9,10-epoxy-8-hydroxy-9-methyl-decatrienoic acid structure (Kohmoto et al. 1993), causes brown spots on citrus leaves and fruit. ACT toxin causes rapid electrolyte leakage from citrus cells and is highly toxic to tangerine (Citrus reticulata Blanco) and grapefruit (Citrus paradisi Macfad.), as well as hybrids from grapefruit and tangerine or tangerine and sweet orange (Citrus sinensis (L.) Osbeck). ACT toxin does not affect rough lemon or Rangpur lime (Kohmoto et al. 1993). As with many Alternaria spp., the genes encoding polypeptides for biosynthesis of ACT toxin likely reside on a dispensable chromosome (Hatta et al. 2002).

The relative roles of ROS in host defense against pathogenic fungi may depend on the lifestyle of the pathogen (Glazebrook 2005). Furthermore, the relative sensitivity of the fungal pathogen to ROS may depend on the effectiveness of its own ROS detoxification machinery. To thrive within the oxidative environment of necrotic tissues, pathogenic fungi have evolved multiple defense systems, both enzymatic and nonenzymatic (Cessna et al. 2000; Mayer et al. 2001; Moye-Rowley 2003). 
In Saccharomyces cerevisiae, the YAP1 transcription factor is one of the most important determinants of the yeast's response to chemical stress, responsible for transcriptional activation of genes involved in ROS detoxification as well as drug and heavy metal resistance (Toone et al. 2001). YAP1 is a leucine zipper-containing transcriptional activator belonging to the mammalian AP1 family (Moye-Rowley 2003). YAP1 is localized in the cytoplasm under normal conditions. Upon exposure to oxidative stresses, YAP1 undergoes a conformational change mediated by the formation of disulfide bonds (Wood et al. 2003; Yan et al. 1998) and is transported into the nucleus where it activates the expression of oxidative stress-associated genes (Toone and Jones 1999). The amino terminal and carboxyl terminal cysteine-rich domains are essential for formation of the disulfide bonds, nuclear localization, and transcriptional activation function of YAP1. Mutation of YAP1 gives rise to fungi that are sensitive to a variety of oxidizing agents, drugs, and xenobiotic compounds (Toone and Jones 1999). YAP1-mediated detoxification of ROS has recently been identified as being an essential virulence determinant in the biotrophic maize pathogen Ustilago maydis (Molina and Kahmann 2007) and the opportunistic human pathogen Candida albicans (Enjalbert et al. 2007). However, YAP1 plays no roles for virulence in the plant pathogen Cochliobolus heterostrophus or the animal pathogen Aspergillus fumigatus (Lessing et al. 2007; Lev et al. 2005).

The mechanism by which phytopathogenic fungi avoid killing by ROS after invasion remains poorly understood. Pathogenic fungi may rely on various strategies to protect themselves from ROS toxicity and survive in the host plant. The objective of this work was to identify the YAP1 homolog in $A$. alternata, to determine whether the gene is involved in the oxidative stress response, and to evaluate whether fungal antioxidant systems are required for A. alternata pathogenicity.

\section{RESULTS}

\section{Cloning and characterization of $A a A P I$.}

Two degenerate primers deduced from the conserved N-terminal cysteine-rich domain of YAP1-like proteins were synthesized and used to amplify a 600-bp DNA fragment from the genome of $A$. alternata. Sequence analysis confirmed that the predicted open reading frame (ORF) of the amplified DNA displayed high similarity to numerous AP1 proteins of fungi and yeasts (Supplementary Fig. 1). The gene was designated A. alternata $A P 1$-like gene $(A a A P 1)$. The entire $A a A P 1$ ORF and its $5^{\prime}$ and $3^{\prime}$ nontranslated regions were amplified with two inverse $A a A P 1$-specific primers from restriction endonucleasedigested and self-ligated DNA templates. Further analysis and comparison of the assembled sequences from cDNA and genomic DNA revealed that the $A a A P 1$ gene has a 2,021-bp ORF interrupted by two small introns of 50 and $81 \mathrm{bp}$. Analysis of sequences 832 bp upstream from the putative ATG translational initiation codon of $A a A P 1$ identified a putative stress responsive element (STRE: AGGGG) found in genes induced by various stresses such as oxidative damage in yeasts (Marchler et al. 1993), one putative binding site (GATA) for the nitrogenregulated AreA and the light-induced WC1/WC2 complex, an ambient pH-regulated PacC-binding motif (GCCAGG), and three cAMP-induced C/EBP-DNA binding motifs (CAAT or CCAAT).

The predicted AaAP1 polypeptide contains 629 amino acids and exhibits substantial similarity (44 to 87\%) and identity (33 to $81 \%$ ) to a number of AP1 homologs and hypothetical proteins identified in fungi and yeasts; AaAP1 is most similar to the AP1-like proteins of Pyrenophora tritici-repentis (XP_ 001931984) and Cochliobolus heterostrophus (AAS64313).
Analysis of the predicted polypeptide of $A a A P l$ identified several conserved domains of YAP1 orthologs (Fig. 1A): a basic leucine zipper (bZIP) DNA-binding domain and a nuclear localization domain (amino acids 161 to 224), an N-terminal cysteine-rich domain (n-CRD; amino acids 387 to 429), and a car-
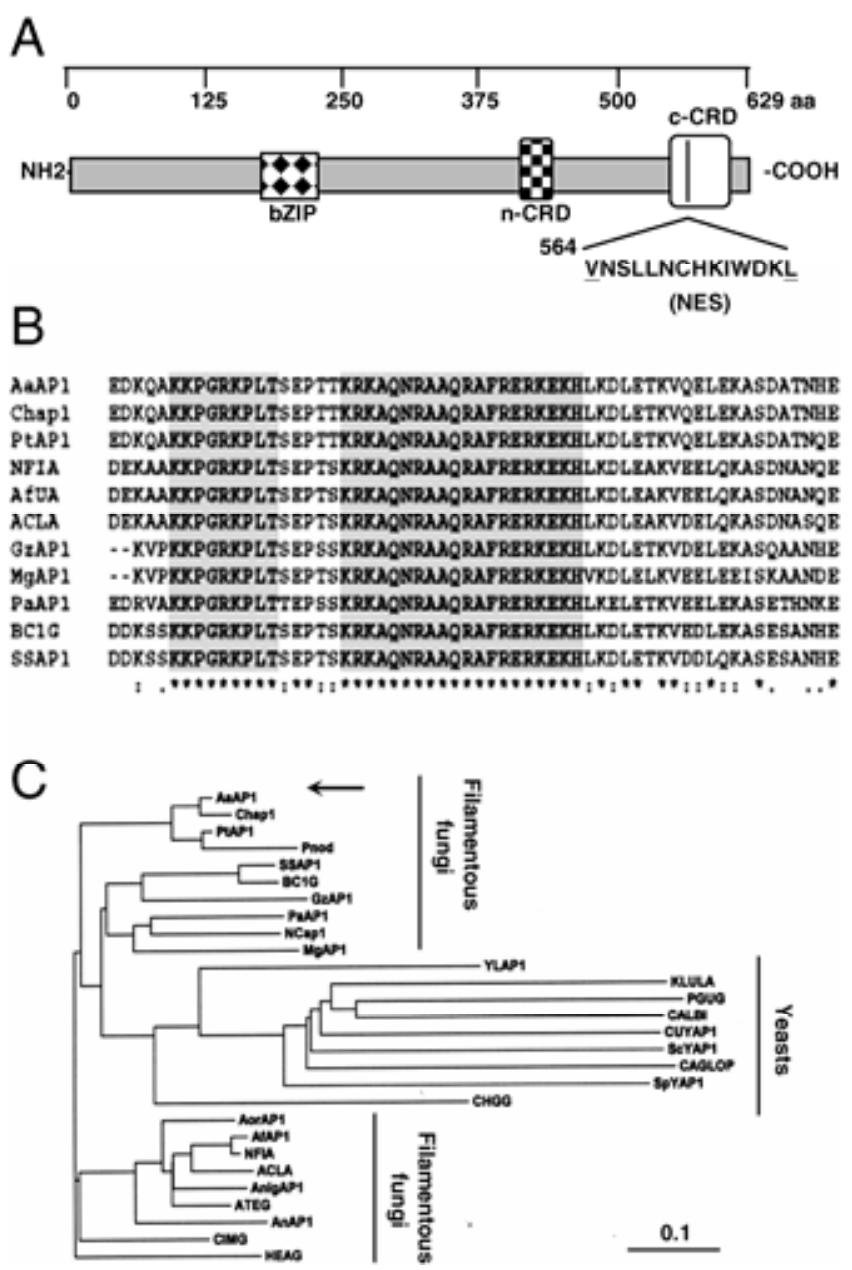

Fig. 1. Functional domains of AaAP1 identified in the tangerine pathotype of Alternaria alternata. A, Physical map of AaAP1 showing conserved functional domains: a basic leucine zipper (bZIP), a cysteine-rich N-terminal domain (n-CRD), a carboxyl-terminal domain (c-CRD), and nuclear export sequence (NES). B, Alignment of the bZIP domain of AaAP1 from A. alternata with those identified in other phytopathogenic fungi. Identical (asterisks), close similar (colons), and more distant similar (periods) amino acid residues are indicated. The conserved bZIP domains are shaded. C, Phylogenetic relationships of AaAP1, inferred from the conserved amino acids in the bZIP domain, in yeast and fungal AP-1 families: Cochliobolus heterostrophus Chap1 (AAS64313), Pyrenophora triticirepentis PtAP1 (XP_001931984), Phaeosphaeria nodorum Pnod (EAT86127), Aspergillus oryzae AorAP1 (BAE92562), A. fumigatus AfAP1 (EAL88844), Neosartorya fischeri NFIA (EAW16217), Sclerotinia sclerotiorum SSAP1 (EDN93694), A. nidulans AnAP1(EAA62093), A. niger AnigAP1(CAK45991), A. clavatus ACLA (EAW06606), Botryotinia fuckeliana BC1G (EDN20443), A. terreus ATEG (EAU33261), Coccidioides immitis CIMG (EAS36028), Ajellomyces capsulatus HEAG (EDN09983), Gibberella zeae GzAP1 (XP_388976), Podospora anserina PaAP1 (CAP66611), Yarrowia lipolytica YLAP1 (CAG77752), Magnaporthe grisea MgAP1 (EDK00544), Chaetomium globosum CHGG (EAQ85132), Neurospora crassa NCap1 (CAB91681), Kluyveromyces lactis KLULA (AAC39320), Pichia guilliermondii PGUG (EDK36566), Pichia jadinii CUYAP1 (BAE48266), Schizosaccharomyces pombe SpYAP1 (CAB66170), Saccharomyces cerevisiae ScYAP1 (CAA41536), Candida glabrata CaGLOP (CAG59929), and C. albicans CALB1 (EAK94712). The phylogram was created with program PHYLP (Saitou and Nei 1987). Each of the branch lengths are proportional to the number of differences in amino acids compared. The horizontal bar indicates the relative distance in the phylogenetic tree. 
boxyl-terminal cysteine-rich domain (c-CRD; amino acids 572 to 605). The strongest similarity was identified in the bZIP, nCRD, and c-CRD domains (Fig. 1B). A putative nuclear export sequence (NES) within the c-CRD (amino acids 564 to 577) is a possible binding site for the Crm1p-like exporter (Yan et al. 1998). Three bipartite nuclear localization signals (NLS) are present between amino acids 142 to 156,152 to 169 , and 166 to 183. AaAP1 contains regions that are rich in aspartic acid (within amino acids 93 to 137), serine (amino acids 336 to 386), and asparagine (amino acids 458 to 467). Phylogenetic relationships of AaAP1 to other fungal and yeast AP1 proteins, inferred from the conserved bZIP domain, revealed that AP1-like proteins are diverse among filamentous fungi yet apparently separated from yeast AP1 orthologs (Fig. 1C).

\section{Targeted disruption of $A a A P 1$.}

A targeted gene-disruption approach (Fig. 2A) was used to determine the function of the AaAPl gene in A. alternata. Two
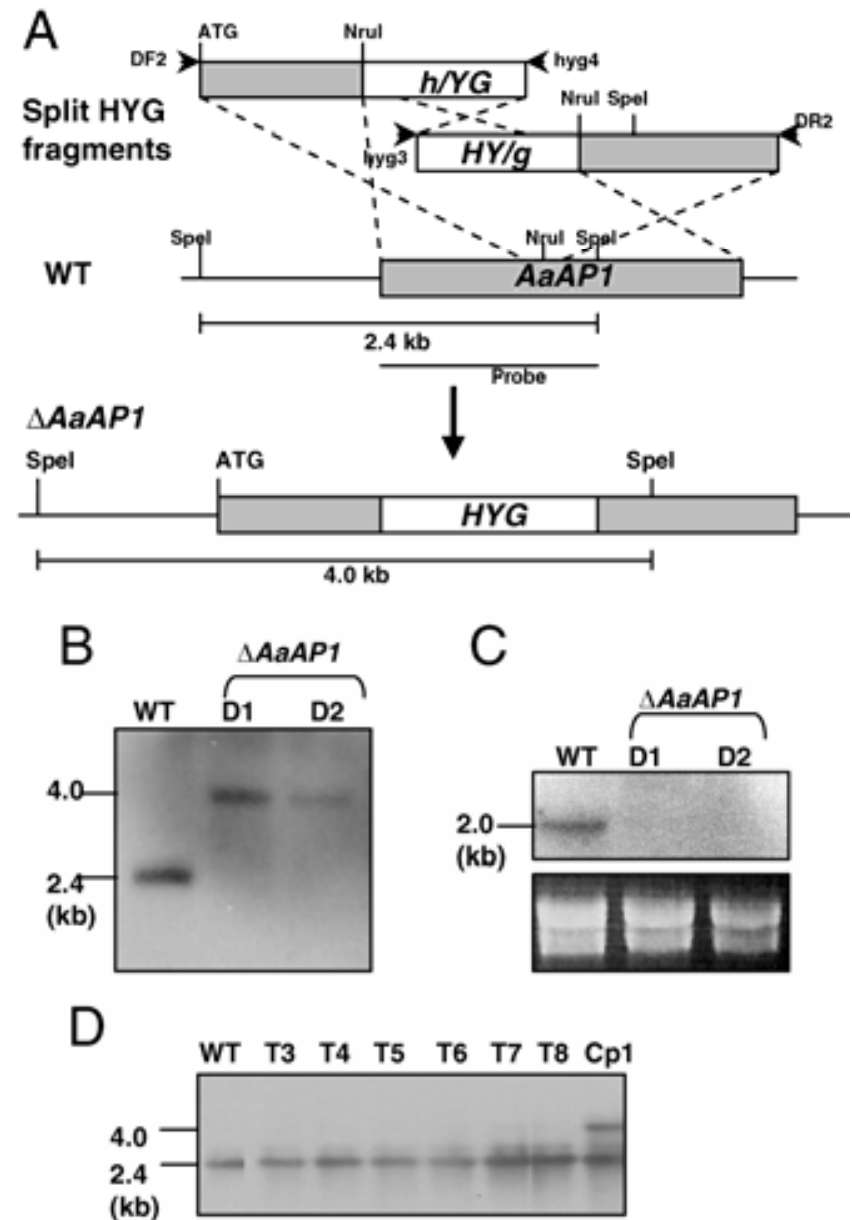

Fig. 2. Targeted disruption of AaAP1 in Alternaria alternata. A, Schematic illustration of a split-marker strategy for disruption of AaAPl (indicated by shaded columns) by inserting a hygromycin phosphotransferase B gene ( $H Y G)$ under control by the Aspergillus nidulans trpC promoter. B, Autographic image of a DNA gel blot of SpeI genomic digests of Alternaria alternata wild type (WT) and $\triangle A a A P 1$ deletion strains D1 and D2 hybridized with a digoxigenin (DIG)-labeled $A a A P 1$ fragment as indicated in A. Hybridizing patterns indicate successful disruption at the AaAP1 locus. C, Image of an RNA gel blot, probed with a DIG-labeled AaAP1, showing a 2-kb AaAPl transcript from the wild type but not from two $\triangle A a A P 1$ deletion strains, D1 and D2. Ribosomal RNA stained with ethidium bromide gives relative loading of the samples. D, Southern blot hybridization of SpeI-digested genomic DNA isolated from the wild type, transformants (T3 to T8) displaying resistance to both hygromycin and $\mathrm{H}_{2} \mathrm{O}_{2}$, and an $A a A P 1$-complemented strain (Cp1) to an $A a A P 1$ probe. hybrid DNA fragments containing a split and truncated hygromycin phosphotransferase B gene $(H Y G)$ marker fused with $5^{\prime}$ or $3^{\prime} A a A P 1$ sequences were amplified from the disruption construct, T-yapHyg, and directly transformed into protoplasts prepared from the wild-type strain of A. alternata. Fungal transformants were recovered from media containing hygromycin and tested for $\mathrm{H}_{2} \mathrm{O}_{2}$ sensitivity. Of 35 transformants screened, two exhibited reduced growth in the presence of $0.1 \% \mathrm{H}_{2} \mathrm{O}_{2}$ and were considered putative $A a A P 1$ disruptants. Southern blot hybridization of SpeI-digested wild-type genomic DNA to an $A a A P 1$ probe identified the expected $2.4-\mathrm{kb}$ hybridizing band (Fig. 2B). However, a 4.0-kb band was detected in DNA of two putative transformants (D1 and D2), resulting from integration of the 1.6-kb $H Y G$ gene cassette at the $A a A P 1$ locus. Northern blot hybridization of total RNA prepared from the wild type and the two putative $A a A P 1$ disruptants revealed that the two transformants were $A a A P 1$-null mutants because they failed to accumulate any detectable $A a A P l$ transcript (Fig. 2C). Southern blot hybridization of genomic DNA prepared from six transformants that were resistant to both hygromycin and $\mathrm{H}_{2} \mathrm{O}_{2}$ to an $A a A P 1$ probe detected the 2.4-kb band of the wild type (Fig. 2D).

\section{AaAP1 contributes to resistance to oxidative stress.}

The AaAPl null mutant reduced growth on regular potato dextrose agar (PDA) by 30 to $33 \%$ compared with the wild type (Fig. 3). Thus, growth reduction greater than $33 \%$ was considered to be indicative of hypersensitivity to the compounds tested. Growth of the $A a A P l$ mutant was inhibited by 82 to $100 \%$ in the presence of $\mathrm{H}_{2} \mathrm{O}_{2}$ or menadione (a superoxide generator) and by 42 to $55 \%$ in the presence of tert-butyl hydroperoxide, sodium dodecyl sulfate (SDS), or potassium superoxide $\left(\mathrm{KO}_{2}\right.$; 1,2.3-benzentriol [ACROS]) (Fig. 3; Supplementary Fig. 2). However, the AaAPl mutant was not sensitive to osmotic and salt stress-related compounds (e.g., sorbitol, mannitol, $\mathrm{NaCl}$, and $\mathrm{KCl}$ ). Beyond hypersensitivity to $\mathrm{H}_{2} \mathrm{O}_{2}$ or menadione, the $A a A P 1$ null mutant retained normal formation and germination of conidia at a rate and magnitude similar to the wild type (data not shown).

The involvement of the $A a A P l$ gene in $\mathrm{H}_{2} \mathrm{O}_{2}$ resistance was further confirmed by genetic complementation. Co-transformation of a copy of the AaAP1 gene under the control of its native promoter with the pCB1532 plasmid (which carries a sulfonylurea resistance (SUR)-selectable marker; discussed below) into protoplasts of the $A a A P 1$ null mutant (D1) resulted in genetically reverted strains with fully restored $\mathrm{H}_{2} \mathrm{O}_{2}$ resistance and other phenotypes comparable with those of the wild type (Fig. 3), indicating that AaAP1 is responsible for resistance to oxidative stress in A. alternata. Southern blot hybridization of SpeI-digested genomic DNA prepared from the complementation strain $\mathrm{Cp} 1$ identified the expected 2.4-kb band, resembling that of the wild type (Fig. 2D). A 4-kb hybridizing band, likely representing the disrupted copy of $A a A P 1$, was also detected in the $\mathrm{Cp} 1$ genomic DNA.

\section{Expression of $A a A P 1$ is responsive to oxidative stress.}

Northern blot analyses were carried out to assess whether expression of the $A a A P 1$ gene responds to $\mathrm{H}_{2} \mathrm{O}_{2}$ and other compounds related to oxidative stress in axenic culture. Accumulation of the 2-kb $A a A P 1$ gene transcript was barely detectable when the fungus was grown on PDA but was elevated in the presence of $\mathrm{H}_{2} \mathrm{O}_{2}$, menadione, and tert-butyl hydroperoxide (Fig. 4A). A similar change in expression of $A a A P 1$ was also observed following a change of growth medium in which the fungal culture was first grown on PDA for 3 days; shifted to a medium containing $\mathrm{H}_{2} \mathrm{O}_{2}, \mathrm{KO}_{2}$, menadione, tert-butyl hydroperoxide, SDS, rose Bengal, or methylthiazolyldiphenyl-tetra- 
zolium bromide (MTT); and incubated for an additional $24 \mathrm{~h}$ prior to RNA purification. The AaAPl gene transcript was barely detectable when the fungal culture was replated on the same medium (PDA) but accumulated to high levels when shifted to a stressor-containing medium, primarily in response to $\mathrm{H}_{2} \mathrm{O}_{2}$, menadione, or tert-butyl hydroperoxide, and to a lesser extent in response to $\mathrm{KO}_{2}$ (Fig. 4B). Expression of $A a A P 1$ was not affected by SDS, rose Bengal, or MTT. Accumulation of catalase, glutathione reductase, or glutathione peroxidase coding gene transcript among the wild-type, AaAPI disruptant, and genetically complemented strains was similar in the presence or absence of $\mathrm{H}_{2} \mathrm{O}_{2}$, as assessed by semiquantitative reverse-transcriptase polymerase chain reaction (RTPCR) (Supplementary Fig. 3).

\section{Nuclear localization}

of AaAP1::sGFP upon exposure to $\mathrm{H}_{2} \mathrm{O}_{2}$.

To investigate whether or not AaAP1 protein is localized in the nucleus under oxidative stress conditions, the $A a A P 1$ gene cassette was translationally fused with a synthetic green fluo-
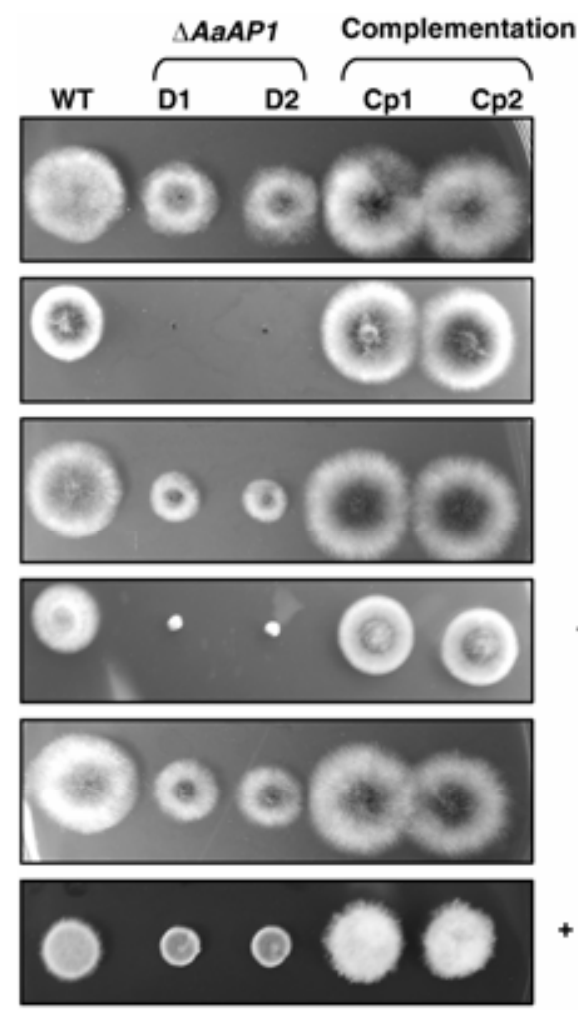

$+100 \mu \mathrm{M}$ Rose Bengal $(34-36 \%)$

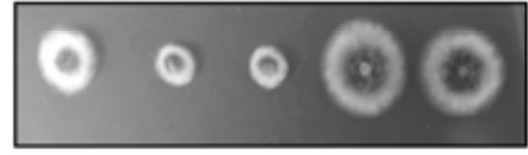

\section{$+0.02 \% \operatorname{SDS}$ $(33-36 \%)$ \\ $+1 \mathrm{mg} / \mathrm{ml}$ MTT $(23-25 \%)$}

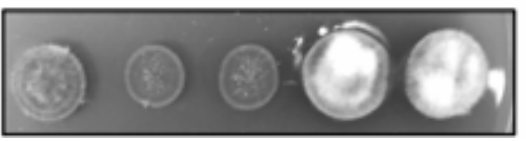

Fig. 3. Alternaria alternata $\triangle A a A P 1$ mutant is hypersensitive to oxidants. Sensitivity of A. alternata wild type (WT), $\triangle A A A P 1$ deletion strains D1 and $\mathrm{D} 2$, and two complementation strains $\mathrm{Cp} 1$ and $\mathrm{Cp} 2$ was determined by radial growth on potato dextrose agar (PDA) supplemented with oxidants or compounds as indicated. Sensitivity (percentage growth reduction) was calculated as a cumulative percentage of growth of WT and $\triangle A a A P I$ deletion strains grown on the same plate. Transformation and expression of a functional $A a A P 1$ gene in the D1 mutant resulted in $\mathrm{Cp} 1$ and $\mathrm{Cp} 2$ strains with restored phenotypes. Only one representative replicate is shown. MTT, methylthiazolyldiphenyl-tetrazolium bromide; SDS, sodium dodecyl sulfate. rescent protein $(s G F P)$ gene. To ascertain that the AaAP1:: sGFP fusion protein is functioning correctly, we first tested the construct for complementation of the D1 null mutant for $\mathrm{H}_{2} \mathrm{O}_{2}$ resistance. Only strains displaying $\mathrm{H}_{2} \mathrm{O}_{2}$ resistance were chosen for microscopic analysis. Expression of $A a A P 1:: s G F P$ under the control of endogenous $A a A P 1$ promoter in the D1 null mutant restored $\mathrm{H}_{2} \mathrm{O}_{2}$ resistance and produced bright green fluorescence in the hyphal cytoplasm under unchallenged conditions (Fig. 5). In contrast, upon exposure to $\mathrm{H}_{2} \mathrm{O}_{2}$, green fluorescence was observed as distinct patches distributed in scattered hyphae exactly resembling those from the 4',6-diamidino2-phenylindole-stained nuclear DNA, implicating nuclear localization of AaAP1::sGFP in response to oxidative stress (Fig. 5).

\section{Downregulation of oxidative stress-related enzymes in the $A a A P 1$ null mutant.}

We measured the overall activities of catalase, peroxidase, and superoxide dismutase (SOD) produced by the AaAP1 null mutant and compared the observed activities with those of the wild type. We found a marked reduction in catalase, peroxidase, and SOD activities in the AaAPl-disrupted mutant (Fig. 6), suggesting that AaAP1 is required for the fungal response to oxidative stress. Indeed, expression of a wild-type AaAPl gene in the D1 null mutant restored the activities of the three antioxidant enzymes to near wild-type levels, further supporting the theory that AaAP1 plays a profound role for oxidative stress resistance and that $A$. alternata is able to detoxify ROS.

$A a A P 1$ plays an essential role during fungal pathogenesis.

Fungal pathogenicity assayed on detached Minneola leaves was evaluated using various inoculation techniques. To determine whether the $A a A P l$ gene is required for fungal patho-

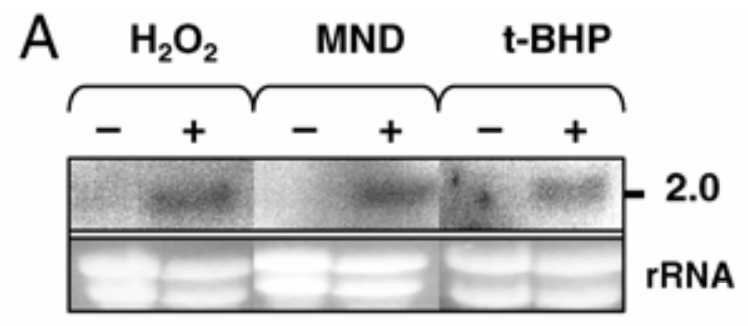

\section{B}

Mock $\mathrm{H}_{2} \mathrm{O}_{2} \quad \mathrm{KO}_{2}$ MND t-BHP MTT RB SDS
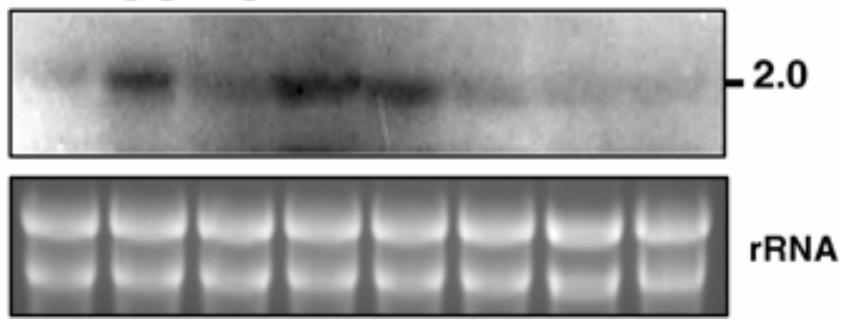

Fig. 4. Accumulation of the $A a A P 1$ transcript of the AaAP1 protein in response to oxidative stress in Alternaria alternata. A, RNA gel blots of wild-type A. alternata grown on potato dextrose agar (PDA) with or without $\mathrm{H}_{2} \mathrm{O}_{2}$, menadione (MND), or tert-butyl hydroperoxide (t-BHP) for 5 days, and hybridized with a digoxigenin-labeled $A a A P 1$ fragment. Gel stained with ethidium bromide indicates relative loading of the RNA samples. B, RNA gel blot of wild-type A. alternata grown on PDA with a layer of cellophane for 3 days and shifted to media containing oxidants or chemicals as indicated. The mock treatment contains RNA obtained from fungal mycelia shifted to the nonamended PDA. MTT, methylthiazolyldiphenyl-tetrazolium bromide; RB, rose Bengal; SDS, sodium dodecyl sulfate. 
genicity and lesion development, conidial suspensions prepared from the wild type, the $A a A P 1$ null mutant, and the genetically reverted $\mathrm{Cp} 1$ strain were inoculated onto detached Minneola leaves. Leaves inoculated with the wild-type suspension developed lesions at 1 or 2 days postinoculation (dpi), appearing as small black spots surrounded by yellow halos. Lesions incited by the wild type continuously expanded, merged, and became irregular black patches of necrotic tissue at 4 dpi (Fig. 7A and B). Necrosis also often occurred along the leaf veins, due to translocation of the host-selective toxin produced by the wild type into the vascular system. By contrast, inoculation of the $A a A P 1$ null mutant using conidial suspension failed to incite necrotic lesions. Occasionally, the AaAP1 null mutant induced small lesions at 4 dpi (Fig. 7A, indicated by arrows); however, this occurred for only $18 \%$ of the total spots inoculated, and such lesions did not expand in size (Fig. 7B). The small lesions were likely caused by limited secretion of the host-selective ACT toxin produced by the $A a A P 1$ mutant. In separate studies, the AaAPl mutant was capable of producing ACT toxin in axenic culture (ChingHsuan Lin, unpublished data). The AaAPl mutant secreted ACT toxin that induced necrosis along the leaf veins on detached Minneola leaves when inoculation was conducted using agar plugs cut from the colony. Pathogenicity assays using conidial suspension revealed that the genetically reverted strains incited necrotic lesions at rates and magnitudes indistinguish-
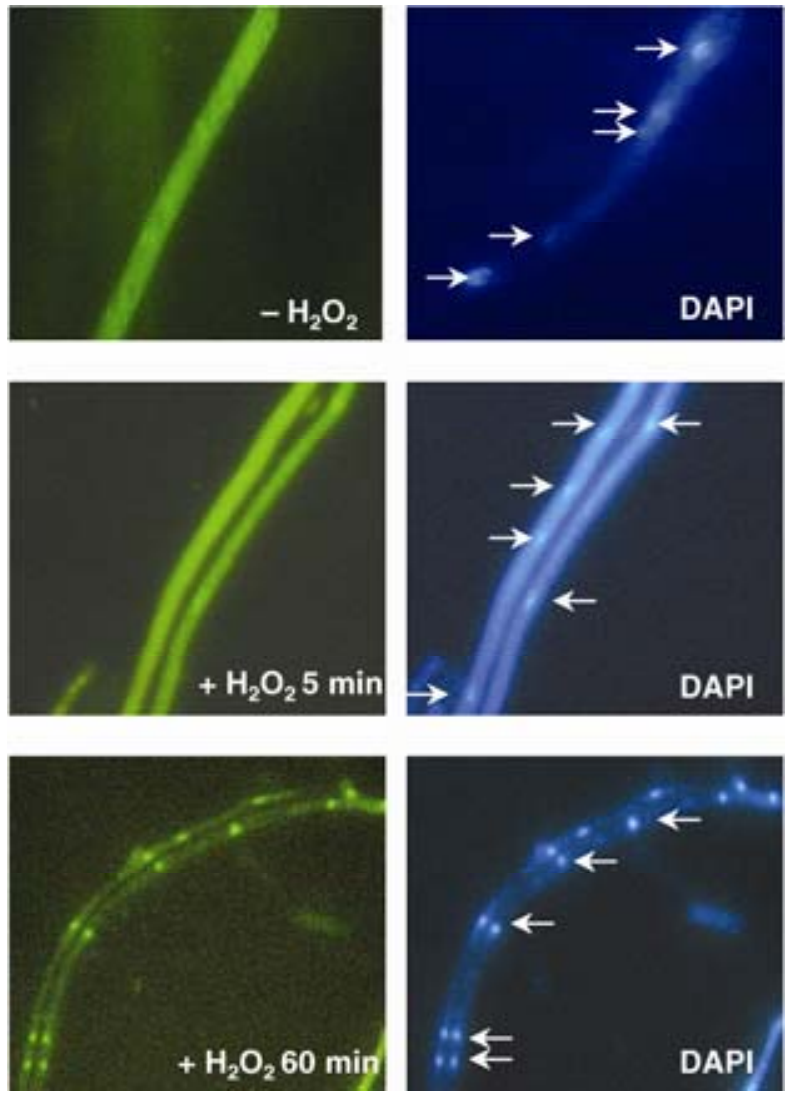

Fig. 5. Expression of the AaAP1::sGFP (synthetic green fluorescent protein) fragment under endogenous $A a A P 1$ promoter in the D1 null mutant restored $\mathrm{H}_{2} \mathrm{O}_{2}$ resistance and produced bright green fluorescence in the hyphal cytoplasm under normal conditions. In contrast, upon exposure to $\mathrm{H}_{2} \mathrm{O}_{2}$ for $60 \mathrm{~min}$, green fluorescence was observed as distinct foci distributed in scattered hyphae, implicating nuclear localization of AaAP1::sGFP. 4'-6-diamidine-2-phenylindole (DAPI) fluorescence indicates distribution of nuclei (indicated by arrows). Fungal isolate was grown in liquid potato dextrose broth for $16 \mathrm{~h}$, treated with or without $\mathrm{H}_{2} \mathrm{O}_{2}$, and examined by fluorescence microscopy. able from those incited by the wild type. Infection assessed on detached leaves sprayed uniformly with conidial suspension also confirmed that the $A a A P l$ mutant is nonpathogenic to Minneola leaves (Fig. 7C). Moreover, the AaAPl null mutant was unable to cause necrotic lesions even when the Minneola leaves were wounded prior to inoculation (Fig. 7D).

\section{The $A a A P 1$ null mutant is impaired} in penetration and colonization stages.

Observations by light microscopy revealed that wild-type $A$. alternata induced necrotic lesions at 2 to $3 \mathrm{dpi}$, resulting in
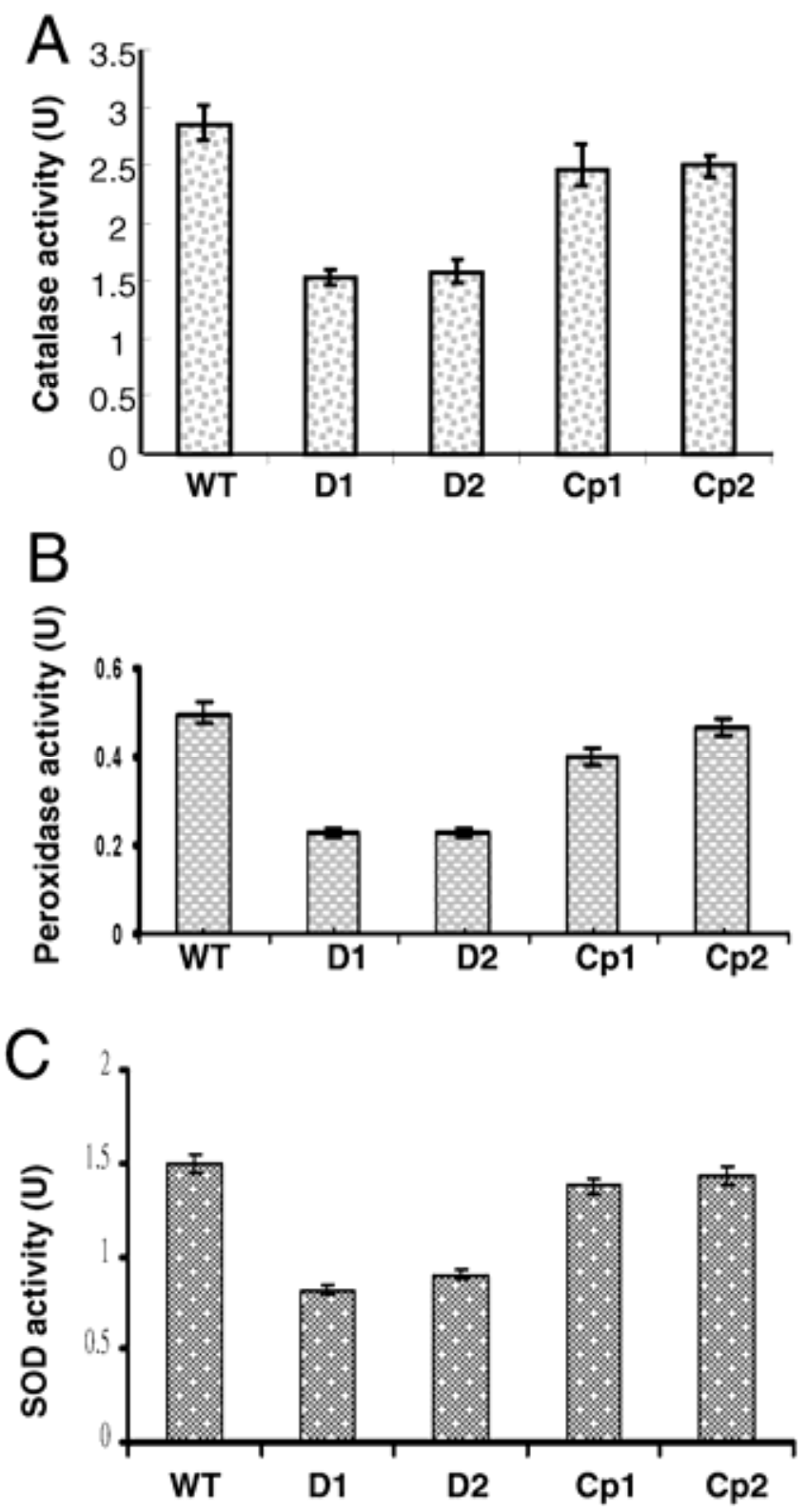

Fig. 6. AaAP1 regulates the production of antioxidant activities in Alternaria alternata. A, Catalase activities in protein crude extract obtained from A. alternata wild type (WT), $\triangle A a A P 1$ deletion strains D1 and D2, and two complementation strains $\mathrm{Cp} 1$ and $\mathrm{Cp} 2$, were assessed by determining the decomposition of $\mathrm{H}_{2} \mathrm{O}_{2}$ in the presence of the colorimetric reagent purpald, and measured spectrophotometrically at absorbance at $550 \mathrm{~nm}$. B, Peroxidase activities were assessed based on the oxidation of pyrogallol in the presence of $\mathrm{H}_{2} \mathrm{O}_{2}$ to form purpurogallin displaying absorbance at $420 \mathrm{~nm}$. C, Superoxide dismutase (SOD) activity was determined by inhibition of the reduction of nitrotetrazolium blue chloride (NTB). The data presented are the mean and standard deviation of two independent experiments with at least three replicates. 
collapse of host tissues in which epidermal layers were disrupted and cellular organelles deformed (Fig. 8A). Germination of conidia and penetration of fungal hyphae occurred within host tissues. By contrast, inoculation with the AaAPIdisrupted mutant did not produce necrotic lesions and did not cause degradation of host organelles (Fig. 8B). Conidia of the mutant germinated well on the leaf surface, indistinguishable from those of the wild type. However, the AaAPI null mutant apparently failed to penetrate the epidermal layer because fungal hyphae were not seen within host tissues. Inoculation of the AaAP1 complementation strain $(\mathrm{Cp} 1)$ produced necrotic lesions and resulted in degradation of host tissues similar to the effects produced by the wild type (data not shown).

\section{NADPH oxidase inhibitors restore pathogenicity of the $A a A P 1$ null mutant.}

Plants produce $\mathrm{H}_{2} \mathrm{O}_{2}$ and superoxide primarily by plasma membrane-bound NADPH oxidases (Doke et al. 1996). A

\section{A}
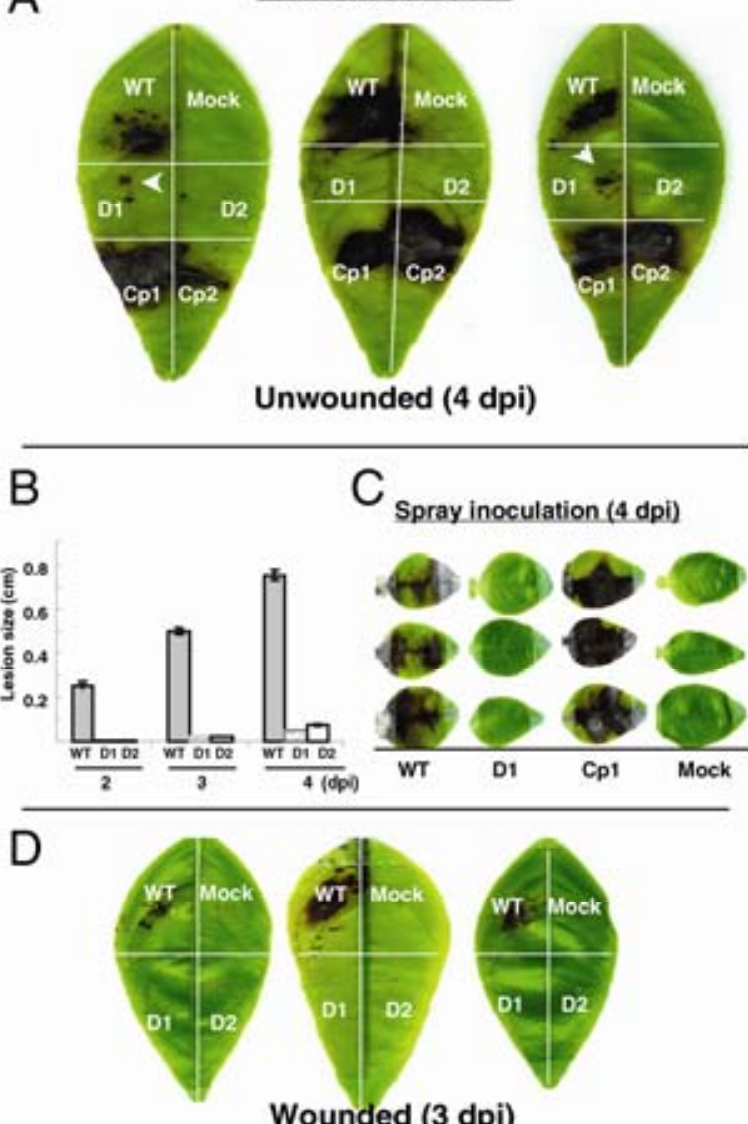

Wounded (3 dpi)

Fig. 7. AaAP1 is indispensable for pathogenicity of Alternaria alternata to citrus cv. Minneola. A, Fungal pathogenicity assayed on detached Minneola leaves inoculated with $10 \mu \mathrm{l}$ of conidial suspension $\left(10^{4}\right.$ conidia/ml $)$ prepared from A. alternata wild type (WT), $\triangle A a A P 1$ deletion strains D1 and D2, and two complementation strains Cp1 and Cp2. The inoculated leaves were incubated in a mist chamber for lesion development. Photos were taken 4 days postinoculation (dpi). The mock controls were treated with water only. Inoculation of the $\triangle A a A P 1$ deletion strain (D1) occasionally produced pinpoint lesions (indicated by arrowheads). Only some representative replicates are shown. B, Quantitative analysis of lesion formation on Minneola leaves inoculated with conidia suspension of A. alternata strains. Lesion diameters were determined at 2, 3, and 4 dpi. C, Fungal pathogenicity assayed on detached Minneola leaves uniformly sprayed with conidial suspension of A. alternata strains. Lesions were recorded at 4 dpi. D, Development of necrotic lesions by A. alternata WT and $\triangle A a A P 1$ deletion strains D1 and D2 on detached Minneola leaves with wounding prior to inoculation. pharmacological approach using NADPH oxidase inhibitors was used to determine whether production of $\mathrm{H}_{2} \mathrm{O}_{2}$ in citrus cells is the primary barrier contributing to the impaired pathogenicity of the AaAPl null mutant. We observed that co-application of apocynin (hydroxy-3-methoxyacetophenone) or diphenylene iodonium (DPI), both NADPH oxidase inhibitors, with an $A a A P 1$ null mutant induced necrotic lesions at 5 dpi, and the lesions continued to expand at 8 dpi (Fig. 9). However, application of apocynin, DPI, or the $A a A P 1$ mutant alone did not cause any visible lesions on Minneola leaves. The rate of lesion formation induced by the $A a A P 1$ null mutant was much lower than that of the wild type. The wild-type isolate of $A$. alternata usually incited necrotic lesions on Minneola leaves at $2 \mathrm{dpi}$; thus, the NADPH oxidase inhibitors only partially restored virulence of the AaAP1 null mutant.

\section{DISCUSSION}

ROS production occurs universally in eukaryotic cells, having roles in cellular defense, cell differentiation, and cell signaling (Aguirre et al. 2005; Apel and Hirt 2004; Mittler 2002; Neill et al. 2002). ROS also are involved in nonhost resistance in

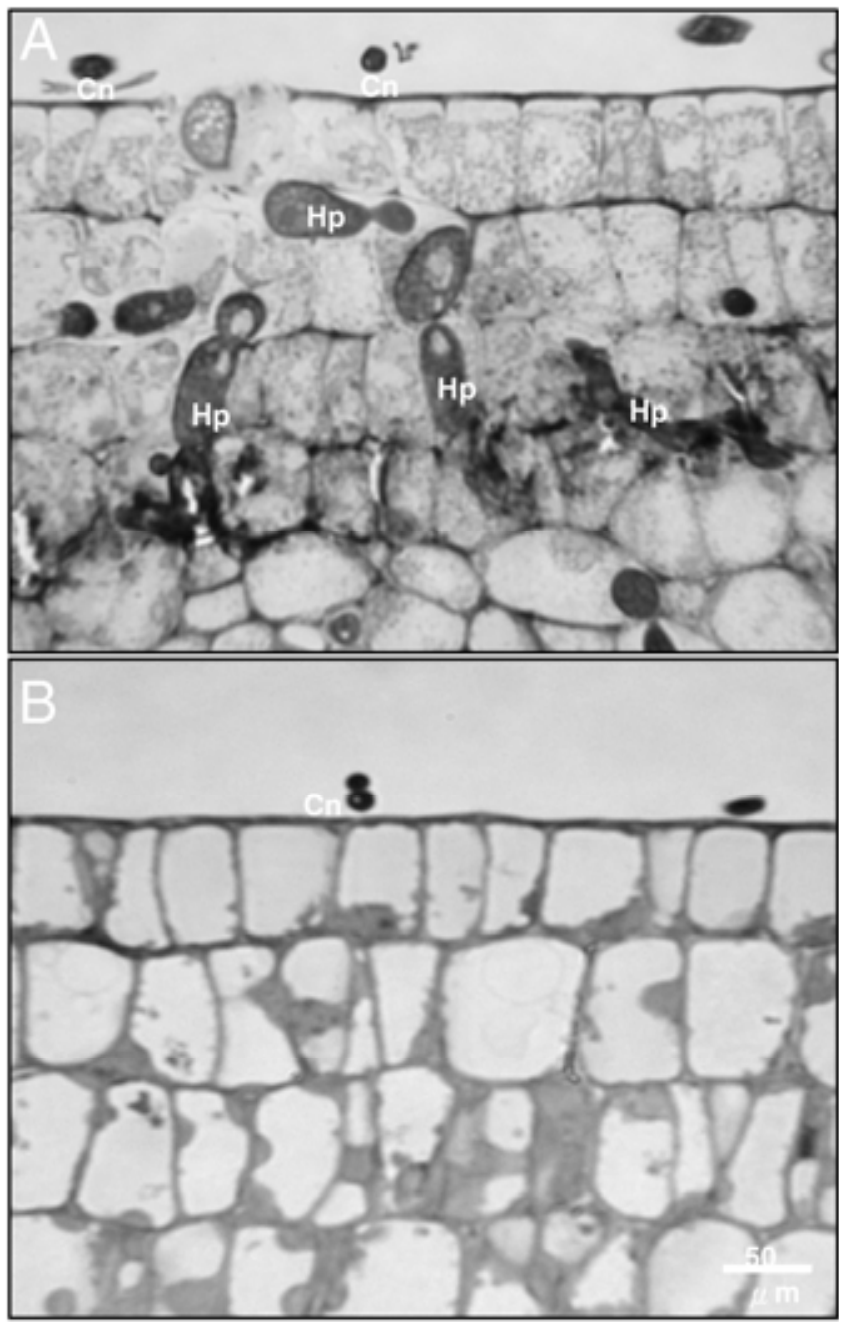

Fig. 8. Light microscopy of Minneola leaves inoculated with Alternaria alternata strains. A, Destruction of Minneola leaf tissues inoculated with wild type (WT) at 2 days postinoculation, showing deformed epidermal layers and cellular organelles and fungal infection hyphae (Hp) and conidia $(\mathrm{Cn})$. B, Inoculation of the $\triangle A a A P 1$ deletion D1 strain onto Minneola leaves shows no signs of tissue deformation and fungal hyphae within the host. 
plants (Narusaka et al. 2005). ROS are toxic to virtually all types of biological macromolecules, including fatty acids, proteins or enzymes, sugars, and nucleic acids; thus, excessive exposure to ROS often results in cell death (Daub et al. 2005). However, all organisms have evolved complex mechanisms to protect against ROS-induced damage (Apel and Hirt 2004; Miller and Britigan 1997; Moye-Rowley 2003; Toone and Jones 1999). Nonetheless, only a few phytopathogenic fungi have been investigated in this respect, and the precise role of antioxidant activity in relation to pathogenicity or virulence of fungal species remains controversial (Giesbert et al. 2008; Keon et al. 2007; Lev et al. 2005; Mayer et al. 2001; Molina and Kahmann 2007; Tanaka et al. 2006).

The role of ROS in host resistance and pathogen invasion is highly dependent on the type of plant-microbe interaction (Hückelhoven and Kogel 2003; Mellersh et al. 2002; Shetty et al. 2007; Takemoto et al. 2007) and may also be influenced by the balance between ROS-generating and ROS-detoxifying systems. Such balance can change quickly owing to changes in host physiology and environmental stimuli. Furthermore, the production of ROS by plants may have different effects against pathogens with different lifestyles (biotrophs versus necrotrophs) (Glazebrook 2005; Spoel et al. 2007). For example, disruption of the CHAPl homolog of the necrotrophic fungus Cochliobolus heterostrophus, which causes southern corn leaf blight, resulted in mutants that are hypersensitive to $\mathrm{H}_{2} \mathrm{O}_{2}$ but of normal virulence (Lev et al. 2005). Similarly, deletion of the Aspergillus fumigatus transcriptional regulator AfYap1 did not affect the pathogenicity of the fungus in an animal model (Lessing et al. 2007). However, recent studies on the biotro-

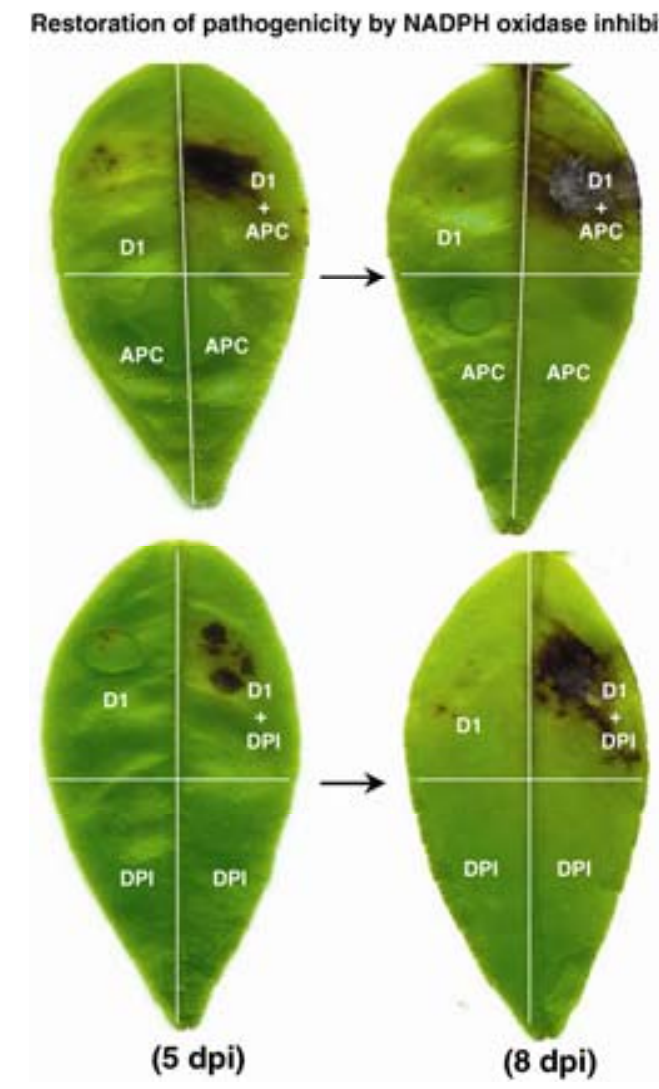

Fig. 9. Application of NADPH oxidase inhibitors restored pathogenicity of the Alternaria alternata $\triangle A a A P 1$ mutant. Pathogenicity and lesion formation were assessed on detached Minneola leaves inoculated with the $\triangle A a A P I$ mutant, NADPH oxidase inhibitors apocynin (APC), and diphenylene iodonium (DPI). The controls were treated with APC or DPI dissolved in dimethyl sulfoxide. phic fungal pathogen $U$. maydis showed that the YAP1-controlled $\mathrm{H}_{2} \mathrm{O}_{2}$ detoxification system plays a role in fungal infection of maize (Molina and Kahmann 2007). Interestingly, the NPS6 gene encoding a nonribosomal peptide synthase has been demonstrated to be involved in siderophore-mediated iron metabolism, resistance to $\mathrm{H}_{2} \mathrm{O}_{2}$, and virulence in several ascomycetic fungi (Lee et al. 2005; Oide et al. 2006). By contrast, ROS acts as a negative regulator in the fungal endophyte Epichlö̈ festuca, likely by prohibiting excessive fungal proliferation and, thus, allowing the fungus to maintain a mutualistic relationship with its host plant (ryegrass, Lolium perenne) (Takemoto et al. 2006). Mutation of an NADPH oxidase gene, noxA, in E. festuca yielded fungal strains that are defective in $\mathrm{H}_{2} \mathrm{O}_{2}$ production yet highly pathogenic to the host plant (Tanaka et al. 2006). By contrast, deletion of the nox-like gene in the ergot pathogen Claviceps purpurea reduced both conidial formation and pathogenicity (Giesbert et al. 2008). NADPH oxidases have also been genetically demonstrated to be critical for pathogenicity both in the rice blast fungus Magnaporthe grisea and in the gray mold fungus $B$. cinerea (Egan et al. 2007; Segmüller et al. 2008).

For Alternaria alternata, B. cinerea, Mycosphaerella graminicola (anamorph: Septoria tritici), and many necrotrophic fungi that obtain nutrients primarily from dead cells, it appears that ROS generation or induction of the HR by the host may actually facilitate colonization (Govrin and Levine 2000; Keon et al. 2007). However, the necrotrophic fungus Sclerotinia sclerotiorum produces oxalic acid that effectively suppresses the ROS produced by the host plant, thus facilitating fungal penetration and colonization (Cessna et al. 2000). To survive in harsh environments, necrotrophic fungi have evolved sophisticated mechanisms for cellular protection against the toxicity of ROS.

Similar to other homologs of the AP1 family (Moye-Rowley 2003; Toone and Jones 1999), AaAP1 contains a conserved leucine zipper (bZIP) domain, a nuclear localization motif, and two regions rich in cysteine residues (n-CRD and c-CRD) that are vital for both cellular localization of YAP1 and YAP1-mediated resistance to oxidative damage (Toone et al. 2001). In yeasts, nuclear localization is a critical step for the function of YAP1 in transcriptional regulation (Coleman et al. 1999). The YAP1 transcription factor, in response to redox or other stressrelated stimuli (e.g., UV, cadmium, and cytotoxic drugs), forms disulfide bonds between intracysteine residues (Coleman et al. 1999). Formation of disulfide bonds in YAP1 leads to the change in protein configuration which disguises the nuclear export motif and prevents binding by the nuclear export protein, Crm1P, thus resulting in nuclear location of YAP1 (Wood et al. 2003; Yan et al. 1998). Substitution of two cysteine residues with arginines within the c-CRD region resulted in cytoplasmic localization of YAP1, due to its inability to form disulfide bonds (Kuge et al. 2001). Nuclear localization of the YAP1-like proteins responding to oxidative stress has been well established in yeasts (Alarco and Raymond 1999; Toone et al. 2001) and Aspergillus fumigatus (Lessing et al. 2007), as well as in phytopathogenic fungi (Lev et al. 2005; Molina and Kahmann 2008). In view of its conserved domains and cysteine residues, it is likely that AaAP1 also fulfills its function by forming disulfide bonds and undergoing appropriate nuclear localization. Indeed, nuclear localization of AaAP1 was also observed in Alternaria alternata in response to $\mathrm{H}_{2} \mathrm{O}_{2}$ stress.

AaAP1-disrupted mutants failed to induce necrotic lesions on detached Minneola leaves even though they retain the ability to synthesize ACT toxin. Wounding the leaves prior to inoculation did not facilitate infection and lesion formation. This nonpathogenic phenotype of the $A a A P 1$ null mutant could be 
associated with reduced activities of fungal antioxidants, including catalase, peroxidase, and SOD, and down-regulation of other antioxidant proteins such as laccase and polyphenol oxidase is also likely (Mayer et al. 2001). Northern blot and semiquantitative RT-PCR analyses, however, revealed no differences for the expression of a copy of catalase, glutathione reductase, and glutathione peroxidase coding genes between the wild-type strain, the $A a A P 1$ disruptant, and the genetically complemented strains in the presence or absence of $\mathrm{H}_{2} \mathrm{O}_{2}$. This is likely due to multiple copies of these genes in A. alternata. However, it was observed that this nonpathogenic phenotype of the AaAPl null mutant is closely associated with reduced activities of fungal antioxidants, including catalase, peroxidase, and SOD. Nonetheless, the inability of the $A a A P 1$ null mutants to incite necrotic lesions is apparently a consequence of their inability to detoxify ROS. Support for this hypothesis was obtained by chemical inhibition of NADPH oxidase, an ROS generator: co-application of AaAPl-disrupted mutants with the inhibitor apocynin or diphenylene iodonium restored lesion-forming capability to the mutants. Thus, in a low-ROS setting, AaAP1-disrupted mutants were able to proliferate and exert pathogenicity.

To provide a framework to better understand the interaction between citrus and A. alternata pathogenicity, a hypothetical model describing the intertwined regulatory controls of AaAP1 is proposed (Fig. 10). In this model, the conidia of A. alternata germinate on the host plant surface and secret ACT toxin, which quickly kills host cells. The dead cells coalesce, forming necrotic lesions, from which the fungal pathogen acquires nutrients and proliferates in the host. Degradation of cell organelles followed by nutrient release may be beneficial to the invading pathogen. Translocation of ACT toxin via the vascular system further exacerbates the necrotic lesions. In response to A. alternata invasion, citrus cells produce ROS mainly via a plasma membrane-anchored NADPH oxidase. Hydrogen peroxide can also be generated from diverse compartments in plant cells (Fig. 10) and has been proposed to play a crucial role in HR and plant resistance against a diverse range of phytopathogens (Greenberg 1997). As with many fungi (Takemoto et al. 2007), A. alternata may contain an NADPH oxidase-coding gene, which likely produces a low level of $\mathrm{H}_{2} \mathrm{O}_{2}$ during early infection. Cell death induced by ACT toxin may release a considerable amount of $\mathrm{H}_{2} \mathrm{O}_{2}$ in the vicinity of the infection court, leading to elevated expression of $A a A P 1$ and nuclear localization of the AaAP1 transcription factor in A. alternata. Subsequently, AaAP1 activates genes whose products are involved in $\mathrm{H}_{2} \mathrm{O}_{2}$ detoxification and cellular protection. Numerous genes involved in the detoxification of ROS have been reported to be regulated by YAP1, including those for catalase, peroxidase, SOD, glutathione reductase, glutathione synthase, thioredoxin reductase, and multidrug resistance transporter (Godon et al. 1998; Toone et al. 2001). Overall, our studies reveal that effective detoxification of ROS via an AaAP1-mediated pathway is critical for successful colonization of citrus by $A$. alternata. Thus, not only is the host-selective toxin produced by $A$. alternata necessary for fungal pathogenicity but so too is AaAP1 as a global regulator of genes involved in ROS resistance.

\section{MATERIALS AND METHODS}

\section{Fungal strains and culture conditions.}

The wild-type EV-MIL31 strain of A. alternata (Fr.) Keissl. used in this study as both a recipient host for transformation and in the mutagenesis experiments was single-conidium cultured from diseased leaves of Minneola tangelo, a hybrid between Duncan grapefruit (Citrus paradisi Macfad.) and Dancy tangerine (Citrus reticulata Blanco) in Florida. Fungal strains were cultured on PDA (Difco, Detroit) at $28^{\circ} \mathrm{C}$. For DNA or RNA purification, fungal strains were grown on agar medium with a layer of sterile cellophane. For preparation of fungal protoplasts, fungal strains were grown in $50 \mathrm{ml}$ of potato dextrose broth (PDB) for 4 to 5 days, blended, mixed with $200 \mathrm{ml}$ of freshly prepared PDB, and incubated for an additional $16 \mathrm{~h}$. Conidia were harvested from fungal cultures grown on PDA under a fluorescent light for 3 to 4 days. Fungal transformants were regenerated from RMM medium containing sucrose at $3.42 \mathrm{~g} / \mathrm{ml}$ as an osmotic reagent as described (Chung et al. 2002). Sensitivity assays to $\mathrm{H}_{2} \mathrm{O}_{2}$ or other chemicals were conducted by transferring fungal mycelia as a toothpick point inoculation onto PDA containing compounds at appropriate concentrations and incubating the mycelia under constant fluorescent light. Fungal radial growth was measured at 4 days. Unless otherwise indicated, all chemicals used in this study were purchased from Sigma-Aldrich-Fluka.

\section{Cloning of $A a A P 1$.}

To obtain a YAP1 homolog, two degenerate primers, AP-1F (5'-AARGARAARCAYYTNAARGAY-3') and AP-1R (5'-GG YTCNGGNSWNGTNCC-3'), that are complementary to the conserved N-terminal cysteine-rich domain were synthesized and used for PCR amplification from genomic DNA of the $A$. alternata EV-MIL31 strain using a Go-Taq DNA polymerase (Promega, Madison, WI, U.S.A.). A 0.6-kb DNA fragment was amplified and cloned into a pGEM-T easy vector (Promega) for sequencing from both directions at Eton Bioscience (San Diego, CA, U.S.A.). The similarity of the amplified fragment was determined by searching against the databases at the

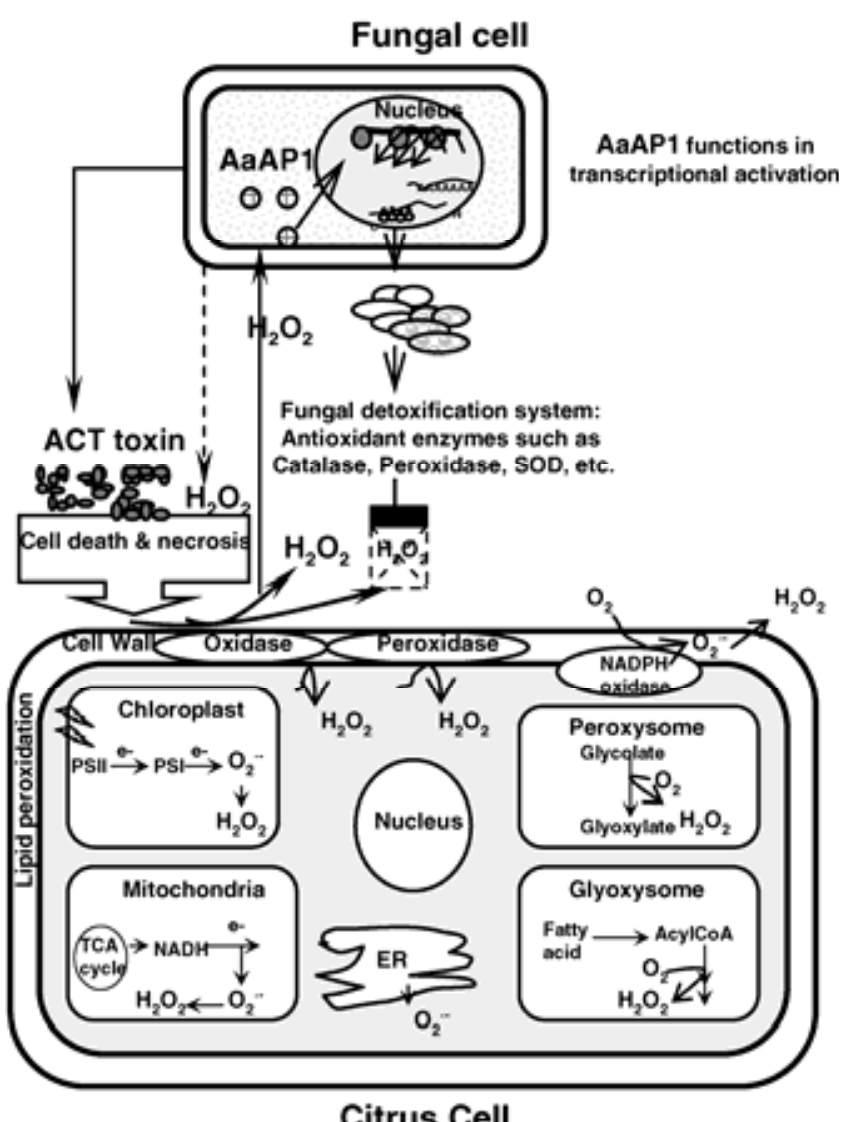

Fig. 10. Proposed regulatory interactions between citrus and Alternaria alternata. Model for AaAP1-mediated regulation and interaction leading to successful colonization and lesion formation in citrus. 
National Center for Biotechnology Information using the BLASTX program. The 5'- and 3'-end sequences of the AaAPI gene were obtained by sequencing a DNA fragment amplified by PCR with two inverse primers ( $5^{\prime}$-ccagggagtccgccaaaacg- $3^{\prime}$ and $5^{\prime}$-cccaggcgctatgacaggca- $3^{\prime}$ ) from endonuclease-clipped and self-ligated genomic DNA pools of $A$. alternata. The promoter region was analyzed using regulatory sequence analysis tools. ORF and exon or intron positions were predicted using Softberry gene-finding software and verified by comparisons of genomic and cDNA sequences. Functional domains were predicted according to the PROSITE database using ExPASy or Motif/ProDom and Block programs. Sequence data from this article can be found in the EMBL/GenBank data libraries under accession number FJ376607.

\section{Creation and identification of the $A a A P 1$ null mutants.}

For targeted gene disruption, a 1.7-kb DNA fragment, encompassing the entire $A a A P l \mathrm{ORF}$ and its $5^{\prime}$ and $3^{\prime}$ nontranslated region, was amplified with primers yap1DF2 (5'-ggctcag acgagcgacacca- $\left.3^{\prime}\right)$ and yap1DR2 (5'-ggagaaccgtatccagtgttgag $\left.\mathrm{g}-3^{\prime}\right)$ and cloned into pGEM-T easy vector to become TyapDFR2. The AaAPl disruption construct, T-yapHyg, was prepared by inserting a $1.6-\mathrm{kb}$ Bam HI fragment of the $H Y G$ cassette under the control of the Aspergillus nidulans trpC gene promoter from pUCATPH at the $\mathrm{NruI}$ site of T-yapDFR2. Two split $H Y G$ fragments fused independently with the truncated $5^{\prime}$ or $3^{\prime}$ end of $A a A P 1$ were amplified from T-yapHyg to facilitate double crossing-over recombination. A $1.5-\mathrm{kb}$ fragment containing the truncated 5' $A a A P l$ and $3^{\prime} H Y G$ was obtained by PCR with primers yap1DF2 and hyg3 (5'-ggatgcetcc gctcgaagta-3'); a 2.1-kb fragment containing $3^{\prime} A a A P 1$ and $5^{\prime}$ $H Y G$ was amplified with primers yapDR2 and hyg4 (5'-cgttgc aagaactgcctgaa-3') (Fig. 2). PCR fragments were directly transformed into protoplasts prepared from the wild-type EV-MIL31 strain of Alternaria alternata, using $\mathrm{CaCl}_{2}$ and polyethylene glycol as previously described (Chung et al. 2002). The $H Y G$ gene is not functional unless homologous recombination takes place between the truncated $H Y G$ DNA fragments. Fungal transformants growing on RMM medium supplemented with hygromycin at $200 \mu \mathrm{g} / \mathrm{ml}$ (Roche Applied Science, Indianapolis, IN, U.S.A.) were picked and tested for $\mathrm{H}_{2} \mathrm{O}_{2}$ sensitivity.

\section{Genetic complementation of an $A a A P 1$-disrupted mutant.}

A functional copy of $A a A P 1$ under control of its endogenous promoter was amplified by a high-fidelity DNA polymerase (Roche Applied Science) using gene-specific primers hypo1 (5'-cgctcagcatatctgtgcgcat- $\left.3^{\prime}\right)$ and yap-taa (5'-ttatccgaggagcttat ctttcgg- $\left.3^{\prime}\right)$. The amplified 3.8-kb fragment was co-transformed with the pCB1532 plasmid harboring the Magnaporthe grisea acetolactate synthase gene cassette that confers sulfonylurea resistance (Sweigard et al. 1997) into protoplasts prepared from an AaAPl null mutant as described (Chung et al. 2002). For GFP expression, the $A a A P 1$ fragment containing its endogenous promoter was translationally in-frame fused with the sGFP coding gene and co-transformed with pCB1532 into protoplasts prepared from a null mutant. Transformants were selected on RMM medium containing sulfonylurea (chlorimuron ethyl) (Chem Service, West Chester, PA, U.S.A.) at $5 \mu \mathrm{g} / \mathrm{ml}$ and examined for $\mathrm{H}_{2} \mathrm{O}_{2}$ sensitivity and for green fluorescence.

\section{Manipulation of nucleic acids.}

Plasmid DNA was propagated in Escherichia coli DH5 $\alpha$ cells and extracted using a Wizard DNA purification kit (Promega). Fungal DNA was purified using a DNeasy plant kit (Qiagen, Valencia, CA, U.S.A.); RNA was obtained with Trizol reagent (Molecular Research Center, Cincinnati, OH, U.S.A.). Double-stranded cDNA of $A a A P l$ was amplified with gene- specific primers from total RNA of A. alternata using a SMARTER cDNA synthesis kit (BD Clontech, Palo Alto, CA, U.S.A.) and cloned into pGEM-T easy vector for sequence analysis. Standard procedures were used for digestion of DNA with restriction endonucleases, electrophoresis, DNA ligation, transformation of bacterial cells, Southern and Northern blot hybridizations, and post-hybridization washing. Molecular probes used for DNA and RNA hybridizations were amplified and labeled by PCR to incorporate digoxigenin-11-dUTP (Roche Applied Science) into a DNA fragment with two AaAP1-specific primers, yap-31 (5'-ccagggagtccgccaaaacg-3') and yap-atg $\left(5^{\prime}\right.$-atggccggaactaccaacgac- $\left.3^{\prime}\right)$. Detection of the probe was performed by an immunological assay using CSPD as a chemofluorescent substrate (Roche Applied Science) for alkaline phosphatase.

\section{Enzymatic assays.}

Fungal proteins were extracted by grinding fungal mycelia in liquid nitrogen mixed with ice-cold potassium phosphate buffer $(250 \mathrm{mM}, \mathrm{pH} 7.0)$ and collecting the supernatant after centrifugation at $10,000 \times g$ for $15 \mathrm{~min}$ at $4^{\circ} \mathrm{C}$. The concentration of crude proteins was determined by a protein assay kit (Bio-Rad, Hercules, CA, U.S.A.). The overall catalase activities were determined by measuring the decomposition of $\mathrm{H}_{2} \mathrm{O}_{2}$ in the presence of a colorimetric reagent, Purpald (4-amino-3hydrazino-5-mercapto-1,2,4-triazol), dissolved in $480 \mathrm{mM}$ hydrochloric acid (Johansson and Håkan Borg 1988). The reaction mixture containing $50 \mu \mathrm{g}$ of crude protein extract (in 100 $\mu \mathrm{l}$ of potassium phosphate buffer), $0.3 \% \mathrm{H}_{2} \mathrm{O}_{2}(10 \mu \mathrm{l})$, and methanol $(50 \mu \mathrm{l})$ was incubated at room temperature $\left(25^{\circ} \mathrm{C}\right)$ for $20 \mathrm{~min}$, stopped by adding $7.8 \mathrm{M}$ potassium hydroxide (50 $\mu l)$ (Fisher Scientific, Pittsburgh) and $100 \mu \mathrm{l}$ of $34.2 \mathrm{mM}$ Purpald solution, incubated for an additional $10 \mathrm{~min}$, and mixed with $50 \mu \mathrm{l}$ of potassium periodate $(65.2 \mathrm{mM}$ dissolved in 470 $\mathrm{mM}$ potassium hydroxide). The reaction was centrifuged at $9,500 \times g$ for $10 \mathrm{~min}$ to remove purple particulates and the supernatant was measured spectrophotometrically with absorbance at $550 \mathrm{~nm}\left(\mathrm{~A}_{550}\right)$. One unit of catalase is defined as that required to decompose $1 \mathrm{mM} \mathrm{H}_{2} \mathrm{O}_{2}$ per minute at $\mathrm{pH} 7.0$ at $25^{\circ} \mathrm{C}$.

Cellular peroxidase activity was assessed using a method based on the oxidation of pyrogallol (ACROS) in the presence of $\mathrm{H}_{2} \mathrm{O}_{2}$ to form purpurogallin (2,3,4,6-tetrahydroxy-5H-benzocycloheptene-5-one), showing $\mathrm{A}_{420}$ (Abrash et al. 1989). The reaction containing $50 \mu \mathrm{g}$ of fungal crude protein extract $(1 \mu \mathrm{l})$, $0.5 \% \mathrm{H}_{2} \mathrm{O}_{2}$, and $5 \%$ pyrogallol dissolved in $100 \mathrm{mM}$ potassium phosphate buffer ( $\mathrm{pH} \mathrm{6.0)}$ was incubated at $25^{\circ} \mathrm{C}$ for $1 \mathrm{~min}$ and measured at $\mathrm{A}_{420}$. The regression line was established using horseradish peroxidise (Sigma). One unit of peroxidase is defined by formation of $1 \mathrm{mg}$ of purpurogallin in $20 \mathrm{~s}$ at $\mathrm{pH} 6.0$ at $20^{\circ} \mathrm{C}$.

SOD activity was determined by inhibition of the reduction of nitrotetrazolium blue chloride to nitroblue tetrazolium (NBT)-diformazan by superoxide radical that is generated by xanthine oxidase during conversion of xanthine to uric acid and $\mathrm{H}_{2} \mathrm{O}_{2}$ (Giannopolitis and Ries 1977). Enzymatic reaction containing $50 \mu \mathrm{g}$ of fungal protein extract, $0.75 \mathrm{mM}$ NBT (80 $\mu \mathrm{l}), 3 \mathrm{mM}$ xanthine $(10 \mu \mathrm{l})$, and 4.4 units of xanthine oxidase was measured at $\mathrm{A}_{550}, 30 \mathrm{~s}$ after incubation. A standard curve was constructed using pure SOD (Sigma). One unit of SOD inhibits $50 \%$ of NBT-diformazan formation under the conditions of the assay. All experiments were carried out two times with at least three replicates.

\section{Determination of fungal pathogenicity.}

Evaluation of fungal pathogenicity was carried out on detached Minneola leaves (4 to 6 days after emergence and 
approximately 3 to $4 \mathrm{~cm}$ in length) inoculated with conidial suspension $\left(1 \times 10^{4}\right.$ conidia/ml $)$. Conidia from fungal isolates grown on PDA at $28^{\circ} \mathrm{C}$ in the light for 5 to 6 days were collected by flooding with sterile water and low-speed centrifugation $(5,000 \times g)$. Conidial suspension was pipetted $(10 \mu \mathrm{l})$ or sprayed with a minisprayer onto detached Minneola leaves and the inoculated leaves were incubated in a mist chamber for 5 to 8 days for lesion development.

\section{Microscopy.}

For light microscopy, plant tissues were stained with methylene blue-Azure A at $65^{\circ} \mathrm{C}$ and examined using a Leitz Laborlux phase-contrast microscope (Leica Microsystems, Exton, PA, U.S.A.). GFP fluorescence was detected using a 450 to 490-nm excitation filter and a 520-nm barrier filter. The images were photographed at 1,024-by-1,024 pixel resolution and exported as TIF files.

\section{ACKNOWLEDGMENTS}

We gratefully acknowledge D. Henderson for initial editing. This research was supported by the Florida Agricultural Experiment Station and grants from the Florida Citrus Production Research Advisory Council.

\section{LITERATURE CITED}

Abrash, H. I., Shih, D., Elias, W., and Malekmehr, F. 1989. A kinetic study of the air oxidation of pyrogallol and purpurogallin. Int. J. Chem. Kinet. 21:465-476.

Aguirre, J., Ríos-Momberg, M., Hewitt, D., and Hansberg, W. 2005. Reactive oxygen species and development in microbial eukaryotes. Trends Microbiol. 13:111-118

Alarco, A. M., and Raymond, M. 1999. The bZip transcription factor Cap1p is involved in multidrug resistance and oxidative stress response in Candida albicans. J. Bacteriol. 181:700-708.

Apel, K., and Hirt, H. 2004. Reactive oxygen species: Metabolism, oxidative stress, and signal transduction. Annu. Rev. Plant Biol. 55:373399.

Branco, M. R., Marinho, H. S., Cyrne, L., and Antunes, F. 2004. Decrease of $\mathrm{H}_{2} \mathrm{O}_{2}$ plasma membrane permeability during adaptation to $\mathrm{H}_{2} \mathrm{O}_{2}$ in Saccharomyces cerevisiae. J. Biol. Chem. 279:6501-6506.

Cessna, S. G., Sears, V. E., Dickman, M. B., and Low, P. 2000. Oxalic acid, a pathogenicity factor for Sclerotinia sclerotiorum, suppresses the oxidative burst of the host plant. Plant Cell 12:2191-2199.

Chung, K. -R., Shilts, T., Li, W., and Timmer, L. W. 2002. Engineering a genetic transformation system for Colletotrichum acutatum, the causal fungus of lime anthracnose and postbloom fruit drop. FEMS (Fed. Eur. Microbiol. Soc.) Microbiol. Lett. 213:33-39.

Coleman, S. T., Epping, E. A., Steggerda, S. M., and Moye-Rowley, W. S. 1999. Yap1p activates gene transcription in an oxidant-specific fashion. Mol. Cell. Biol. 19:8302-8313.

Daub, M. E., Herrero, S., and Chung, K. -R. 2005. Photoactivated perylenequinone toxins in fungal pathogenesis of plants. FEMS (Fed. Eur. Microbiol. Soc.) Microbiol. Lett. 252:197-206.

Divon, H. H., and Fluhr, R. 2007. Nutrition acquisition strategies during fungal infection of plants. FEMS (Fed. Eur. Microbiol. Soc.) Microbiol. Lett. 266:65-74

Doke, N., Miura, Y., Sanchez, L. M., Park, H. J., Noritake, T., Yoshioka, H., and Kawakita, K. 1996. The oxidative burst protects plants against pathogen attack: Mechanism and role as an emergency signal for plant bio-defence-a review. Gene 179:45-51.

Egan, M. J., Wang, Z.-Y., Jones, M. A., Smirnoff, N., and Talbot, N. J. 2007. Generation of reactive oxygen species by fungal NADPH oxidases is required for rice blast disease. Proc. Natl. Acad. Sci. U.S.A. 104:11772-11777.

Enjalbert, B., MacCallum, D. M., Odds, F. C., and Brown, A. J. P. 2007. Niche-specific activation of the oxidative stress response by the pathogenic fungus Candida albicans. Infect. Immun. 75:2143-2151.

Giannopolitis, C. N., and Ries, S. K. 1977. Superoxide dismutases: Occurrence in higher plants. Plant Physiol. 59:309-314.

Giesbert, S., Schürg, T., Scheele, S., and Tudzynski, P. 2008. The NADPH oxidase Cpnox 1 is required for full pathogenicity of the ergot fungus Claviceps purpurea. Mol. Plant Pathol. 9:317-327.

Glazebrook, J. 2005. Contrasting mechanisms of defense against biotrophic and necrotrophic pathogens. Annu. Rev. Phytopathol. 43:205-227.
Godon, C., Langniel, G., Lee, J., Buhler, J. M., Kieffer, S., Perrot, M., Boucherie, H., Toledano, M. B., and Labarre, J. 1998. The $\mathrm{H}_{2} \mathrm{O}_{2}$ stimulon in Saccharomyces cerevisiae. J. Biol. Chem. 273:2248022489.

Govrin, E. M., and Levine, A. 2000. The hypersensitive response facilitates plant infection by the necrotrophic pathogen Botrytis cinerea. Curr. Biol. 10:751-757.

Greenberg, J. T. 1997. Programmed cell death in plant-pathogen interactions. Annu. Rev. Plant. Physiol. Plant Mol. Biol. 48:525-545.

Hatta, R., Ito, K., Hosaki, Y., Tanaka, T., Tanaka, A., Yamamoto, M., Akimitsu, K., and Tsuge, T. 2002. The conditionally dispensable chromosome controls host-specific pathogenicity in the fungal plant pathogen Alternaria alternata. Genetics 161:59-70.

Hückelhoven, R., and Kogel, K.-H. 2003. Reactive oxygen intermediates in plant-microbe interactions: Who is who in powdery mildew resistance? Planta 216:891-902.

Imlay, J. A 2003. Pathways of oxidative damage. Annu. Rev. Microbiol. 57:395-418.

Ito, K., Tanaka, T., Hatta, R., Yamamoto, M., Akimitsu, K., and Tsuge, T. 2004. Dissection of the host range of the fungal plant pathogen Alternaria alternata by modification of secondary metabolism. Mol. Microbiol. 52:399-411.

Johansson, L. H., and Håkan Borg, L. A. 1988. A spectrophotometric method for determination of catalase activity in small tissue samples. Anal. Biochem. 174:331-336.

Keon, J., Antoniw, J., Carzaniga, R., Deller, S., Ward, J. L., Baker, J. M., Beale, M. H., Hammond-Kosack, K., and Rudd, J. J. 2007. Transcriptional adaptation of Mycosphaerella graminicola of programmed cell death (PCD) of its susceptible wheat host. Mol. Plant-Microbe Interact. 20:178-193.

Kohmoto, K., Akimitsu, K., and Otani, H. 1991. Correlation of resistance and susceptibility of citrus to Alternaria alternata with sensitivity to host-specific toxins. Phytopathology 81:719-722.

Kohmoto, K., Itoh, Y., Shimomura, N., Kondoh, Y., Otani, H., Nishimura, S., and Nakatsuka, S. 1993. Isolation and biological activities of two host-specific toxins from tangerine pathotype of Alternaria alternata. Phytopathology 83:495-502.

Kuge, S., Arita, M., Murayama, A., Maeta, K., Izawa, S., Inoue, Y., and Nomoto, A. 2001. Regulation of yAP-1 nuclear export signal is mediated by redox signal-induced reversible disulfide bond formation. Mol. Cell. Biol. 21:6139-6150.

Lee, B.-N., Kroken, S., Chou, D. Y. T., Robbertse, B., Yoder, O. C., and Turgeon, B. G. 2005. Functional analysis of all non-ribosomal peptide synthases in Cochliobolus heterostrophus reveals a factor, NPS6, involved in virulence and resistance to oxidative stress. Eukaryot. Cell 4:545-555.

Lessing, F., Kniemeyer, O., Wozniok, I., Loeffler, J., Kurzai, O., Haertl, A., and Brakhage, A. A. 2007. The Aspergillus fumigatus transcriptional regulator AfYap1 represents the major regulator for defense against reactive oxygen intermediates but is dispensable for pathogenicity in an intranasal mouse infection model. Eukaryot. Cell 6:2290-2302.

Lev, S., Hadar, R., Amedeo, P., Baker, S., Yoder, O. C., and Horwitz, B. A. 2005. Activation of an AP-1-like transcription factor of the maize pathogen Cochliobolus heterostrophus in response to oxidative stress and plant signals. Eukaryot. Cell 4:443-454.

Marchler, G., Schuller, C., Adam, G., and Ruis, H. A. 1993. A Saccharomyces cerevisiae UAS element controlled by protein kinase A activates transcription in response to a variety of stress conditions. EMBO (Eur. Mol. Biol. Organ.) J. 12:1997-2003.

Mayer, A. M., Staples, R. C., and Gil-ad, N. L. 2001. Mechanisms of survival of necrotrophic fungal pathogens in hosts expressing the hypersensitive response. Phytochemistry 58:33-41.

Mellersh, D. G., Foulds, I. V., Higgins, V. J., and Heath, M. C. 2002. $\mathrm{H}_{2} \mathrm{O}_{2}$ plays different roles in determining penetration failure in three diverse plant-fungal interactions. Plant J. 29:257-268.

Miller, R. A., and Britigan, B. E. 1997. Role of oxidants in microbial pathophysiology. Clin. Microbiol. Rev. 10:1-18.

Mittler, R. 2002. Oxidative stress, antioxidants and stress tolerance. Trends Plant Sci. 7:405-410.

Molina, L., and Kahmann, R. 2007. An Ustilago maydis gene involved in $\mathrm{H}_{2} \mathrm{O}_{2}$ detoxification is required for virulence. Plant Cell 19:2293-2309.

Moye-Rowley, W. S. 2003. Regulation of the transcriptional response to oxidative stress in fungi: Similarities and differences. Eukaryot. Cell 2:381-389.

Narusaka, Y., Narusaka, M., Seki, M., Ishida, J., Shinozaki, K., Nan, Y. Park, P., Shiraishi, T., and Kobayashi, M. 2005. Cytological and molecular analyses of non-host resistance of Arabidopsis thaliana to Alternaria alternata. Mol. Plant Pathol. 6:615-627.

Neill, S., Desikan, R., and Hancock, J. 2002. Hydrogen peroxide signaling. Curr. Opin. Plant Biol. 5:388-395. 
Oide, S., Moeder, W., Krasnoff, S., Gibson, D., Haas, H., Yoshioka, K. and Turgeon, B. G. 2006. NPS6, encoding a nonribosomal peptide synthase involved in siderophore-mediated iron metabolism, is a conserved virulence determinant of plant pathogenic ascomycetes. Plant Cell 18:2836-2853.

Saitou, N., and Nei, M. 1987. The neighbor-joining method: A new method for reconstructing phylogenetic trees. Mol. Biol. Evol. 4:406-425.

Segmüller, N., Kokkelink, L., Giesbert, S., Odinius, D., van Kan, J., and Tudzynski, P. 2008. NADPH oxidases are involved in differentiation and pathogenicity in Botrytis cinerea. Mol. Plant-Microbe Interact. 21:808-819.

Shetty, N. P., Mehrabi, R., Lutken, H., Haldrup, A., Kema, G. H. J. Collinge, D. B., and Jørgensen, H. J. L. 2007. Role of hydrogen peroxide during the interaction between the hemibiotrophic fungal pathogen Septoria tritici and wheat. New Phytol. 174:637-647.

Spoel, S. H., Johnson, J. S., and Dong, X. 2007. Regulation of tradeoffs between plant defenses against pathogens with different lifestyles. Proc. Natl. Acad. Sci. U.S.A. 104:18842-18847.

Sweigard, J. A., Chumley, F. C., Carroll, A. M., Farrall, L. and Valent, B. 1997. A series of vectors for fungal transformation. Fungal Genet. Newsl. 44:52-53.
Takemoto, D., Tanaka, A., and Scott, B. 2006. A p67 ${ }^{\text {Phox }}$-like regulator is recruited to control hyphal branching in a fungal-grass mutualistic symbiosis. Plant Cell 18:2807-2821.

Takemoto, D., Tanaka, A., and Scott, B. 2007. NADPH oxidase in fungi: Diverse roles of reactive oxygen species in fungal cellular differentiation. Fungal Genet. Biol. 44:1065-1076.

Tanaka, A., Christensen, M. J., Takemoto, D., Park, P., and Scott, B. 2006. Reactive oxygen species play a role in regulating a fungus-perennial ryegrass mutualistic interaction. Plant Cell 18:1052-1066.

Toone, W. M., and Jones, N. 1999. AP-1 transcription factors in yeast. Curr. Opin. Genet. Dev. 9:55-61.

Toone, W. M., Morgan, B. A., and Jones, N. 2001. Redox control of AP-1like factors in yeast and beyond. Oncogene 20:2336-2346.

Veal, E. A., Day, A. M., and Morgan, B. A. 2007. Hydrogen peroxide sensing and signaling. Mol. Cell 26:1-14.

Wood, M. J., Andrade, E. C., and Storz, G. 2003. The redox domain of Yap1p transcription factor contains two disulfide bonds. Biochemistry 42:11982-11991.

Yan, C., Lee, L. H., and Davis, L. I. 1998. Crm1p mediates regulated nuclear export of a yeast AP-1-like transcription factor. EMBO (Eur. Mol Biol. Organ.) J. 17:7416-7429. 